\title{
Ventilation heterogeneity in the acinar and conductive zones of the normal ageing lung
}

\author{
Sylvia Verbanck, ${ }^{1}$ Bruce R Thompson, ${ }^{2}$ Daniel Schuermans, ${ }^{1}$ Harpal Kalsi, ${ }^{3}$ \\ Martyn Biddiscombe, ${ }^{3}$ Chris Stuart-Andrews, ${ }^{2}$ Shane Hanon, ${ }^{1}$ Alain Van Muylem, \\ Manuel Paiva, ${ }^{4}$ Walter Vincken, ${ }^{1}$ Omar Usmani ${ }^{3}$
}

\begin{abstract}
- Additional materials are published online only. To view these files please visit the journal online (http://dx.doi.org/ 10.1136/thoraxjn-2011201484).

${ }^{1}$ Respiratory Division, University Hospital UZ Brussel, Brussels, Belgium

${ }^{2}$ Allergy, Immunology and Respiratory Medicine, The Alfred Hospital, Melbourne, Australia

${ }^{3}$ Imperial College London and Royal Brompton Hospital, National Heart and Lung Institute, London, UK ${ }^{4}$ Respiratory Division, University Hospital Erasme, Université Libre de Bruxelles, Brussels, Belgium
\end{abstract}

\section{Correspondence to}

Dr Sylvia Verbanck, Respiratory Division, University Hospital UZ Brussel, Laarbeeklaan 101, 1090 Brussels, Belgium; sylvia.verbanck@uzbrussel.be

Received 8 December 2011 Accepted 28 March 2012 Published Online First 27 April 2012

\section{ABSTRACT}

Rationale Small airways function studies in lung disease have used three promising multiple breath washout (MBW) derived indices: indices of ventilation heterogeneity in the acinar $\left(\mathrm{S}_{\text {acin }}\right)$ and conductive $\left(\mathrm{S}_{\text {cond }}\right)$ lung zones, and the lung clearance index (LCI). Since peripheral lung structure is known to change with age, ventilation heterogeneity is expected to be affected too. However, the age dependence of the MBW indices of ventilation heterogeneity in the normal lung is unknown. Objectives The authors systematically investigated $\mathrm{S}_{\text {acin }}, \mathrm{S}_{\text {cond }}$ or $\mathrm{LCl}$ as a function of age, testing also the robustness of these relationships across two laboratories.

Methods MBW tests were performed by never-smokers $(50 \% \mathrm{men})$ in the age range $25-65$ years, with data gathered across two laboratories $(n=120$ and $n=60)$. For comparison with the literature, the phase III slopes from classical single breath washout tests were also acquired in one group ( $n=120)$.

Measurements and main results All three MBW indices consistently increased with age, representing a steady worsening of ventilation heterogeneity in the age range $25-65$. Age explained $7-16 \%$ of the variability in $S_{\text {acin }}$ and $S_{\text {cond }}$ and $36 \%$ of the variability in $\mathrm{LCl}$. There was a small but significant gender difference only for $S_{\text {acin }}$. Classical single breath washout phase III slopes also showed age dependencies, with gender effects depending on the normalisation method used.

Conclusions With respect to the clinical response, age is a small but consistent effect that needs to be factored in when using the MBW indices for the detection of small airways abnormality in disease.

\section{INTRODUCTION}

The multiple breath washout (MBW) test has been advocated for small airways detection in obstructive lung disease. ${ }^{12}$ Initially propelled by paediatric clinical lung research but now also promoted in adult lung disease, the most frequently reported $\mathrm{MBW}$ index is the lung clearance index (LCI). ${ }^{3-5}$ First introduced in 1951 as a measure of overall lung ventilation heterogeneity, ${ }^{6} \mathrm{LCI}$ is currently deemed useful in the early detection of cystic fibrosis lung disease, ${ }^{3}$ with the specific advantages that LCI requires no particular breathing volumes and is quasi independent of lung growth (1-17 years). ${ }^{7}$ In adults, an analysis of the MBW phase III slope was proposed to distinguish ventilation heterogeneity generated in acinar air spaces from that originating

\section{Key messages}

What is the key question?

- It has been shown that alveolar architecture changes with age, however the age dependence of lung function indices that can actually measure functional change in the alveolar region have yet to be investigated.

What is the bottom line?

- If the alveolar architecture changes with age are large enough to be reflected functionally in small airway indices, these need to be acknowledged because early changes in the small airways may be a normal ageing effect.

\section{Why read on?}

- While previous studies clearly show clinical usefulness of indices that reflect gas mixing within the small airways, this study illustrates how neglecting the effect of age can unduly lead to diagnosis of small airway dysfunction in older people.

in the more proximal lung. ${ }^{8}$ The two most relevant $M B W$-derived indices of ventilation heterogeneity are referred to as $S_{\text {acin }}$ (for ventilation heterogeneity generated peripheral to the acinar entrance) and $\mathrm{S}_{\text {cond }}$ (for ventilation heterogeneity generated in the conductive lung zone). An exhaustive review of theory and experiments underpinning this phase III slope analysis are part of a recent update of the Handbook of Physiology, and the most critical aspects are iterated in the online supplement. Due to intrinsic structural heterogeneity of the airways within the lungs, $S_{\text {acin }}$ and $S_{\text {cond }}$ are non-zero in the normal lung, but show marked increases in lung disease..$^{10-16}$ In patients with chronic obstructive pulmonary disease those with emphysema show a greater $S_{\text {acin }}{ }^{10}$; the extent of $S_{a c i n}$ increase is associated with carbon monoxide transfer factor, ${ }^{11}$ and with high-resolution CT lung density. ${ }^{12}$ In asthma, patients with an increased $S_{\text {acin }}$ are better responders to small particle-sized corticosteroids, ${ }^{13}$ and $S_{a c i n}$ correlates with an increased alveolar nitric oxide. ${ }^{14}$ In adult asthma, $\mathrm{S}_{\text {cond }}$ is a predictor of airway hyperresponsiveness, independent of inflammation, ${ }^{15}$ and in preschool wheezers $S_{\text {cond }}$ is a sensitive indicator of abnormal pulmonary function. ${ }^{16}$ 
To date, no comprehensive reports exist of LCI, $\mathrm{S}_{\text {acin }}$ and $\mathrm{S}_{\text {cond }}$ values and their dependence on age in a normal adult population. On the one hand, early physiological studies using the phase III slope of the single breath washout (SBW) following a 1 litre oxygen inhalation have indicated an age dependence of ventilation heterogeneity. ${ }^{17}{ }^{18}$ In later studies, age dependence of the vital capacity SBW phase III slope-which includes a gravitational component ${ }^{19}$ - was found to be either non-existent, ${ }^{20}$ or poor up to the age of $55-60$ years. ${ }^{21-23}$ On the other hand, histological evidence, ${ }^{24}$ and indirect measurement by MRI, ${ }^{25}$ have demonstrated alveolar size increases in the normal lung between 25 and 65 years. This is expected to impact on ventilation heterogeneity in the most peripheral acinar lung units (potentially affecting $S_{\text {acin }}$ ) but also on the elastic properties of clusters of acini (potentially affecting $S_{\text {cond }}$ ). Given the potential associations between LCI and $\mathrm{S}_{\text {acin }}$ or $\mathrm{S}_{\text {cond, }}{ }^{26}{ }^{27} \mathrm{LCI}$ is also likely to be affected in a normal ageing adult lung, as opposed to age independence of LCI in children. ${ }^{7}$ We therefore hypothesised that while $S_{\text {acin }}$ is the most likely MBW index to be age dependent, $S_{\text {cond }}$ and LCI may be affected by age as well.

\section{MATERIALS AND METHODS}

MBW tests were collected on never-smoker healthy subjects in the age range 25-65 years, in two laboratories $(n=120$ and $n=60)$. To test the potential for automated analysis of such large MBW datasets for future clinical use, similar to that previously done for the SBW test, ${ }^{28}$ we also submitted a data subset for semi-automated analysis recently developed by a third participating laboratory. ${ }^{29}$ The study protocols at UZ Brussel (core dataset site) and Brompton Hospital (supplemental dataset site) were approved by the respective local research ethics committee (B14320097554; 08/H0709/2). All participating subjects were Caucasian, were not obese (defined as a body mass index >30) and were defined as healthy through clinical screening according to the following: an absence of history of symptoms suggestive of respiratory disease, no childhood or past medical history of respiratory disease, and had never smoked. Subject recruitment was undertaken through open advertisement in an intention-toenter manner to avoid potential bias or lack of representativeness of the population at large. All subjects provided written informed consent prior to testing.

\section{Core dataset (UZ Brussel; $\mathbf{n = 1 2 0}$ )}

After standard spirometry, MBW and SBW tests were performed in triplicate on 120 subjects (15 men/15 women in each decade between 25 and 65 years of age). The MBW test involved 1 litre tidal breathing from functional residual capacity (FRC). The SBW test was performed as two previously used maneuvers ${ }^{17} 18$ 20-22. either a one-litre inspiration from FRC with expiration to residual volume $\left(S_{B} W_{F R C}\right)$ or a vital capacity inspiration with expiration to back to residual volume $\left(\mathrm{SBW}_{\mathrm{RV}}\right)$. A bag-in-box and valve system was used, with a re-inspired dead space (ie, re-inspired volume in subsequent MBW inhalations) amounting to $50 \mathrm{ml}$, and a $\mathrm{N}_{2}$ analyser (PK-Morgan, Rainham, UK).

\section{Supplemental dataset (Brompton Hospital; $\mathbf{n}=\mathbf{6 0}$ )}

After spirometry, MBW tests were performed in triplicate on 60 subjects between 25 and 65 years, with an even spread of gender across the age range studied. The equipment was very similar to the UZ Brussel bag-in-box setup, with a re-inspired dead space of $15 \mathrm{ml}$, and a $\mathrm{N}_{2}$ analyser (Logan Research, Rochester, UK).
After accounting for synchronisation between $\mathrm{N}_{2}$ and pneumotachograph signals and re-inspired dead space specific to core and supplemental datasets, MBW tests were analysed as per the instructions provided by one of the authors (MP) common to the present and the original paper on $\mathrm{MBW}$ analysis. ${ }^{8}$ To this end, custom-built manually operated software was used by authors SV and MP to determine phase III slopes (nominally between 0.65 and 1 litre) from each breath of the MBW test. The phase III slopes were normalised by the mean expired $\mathrm{N}_{2}$ concentration, plotted against lung turnover, and $\mathrm{S}_{\mathrm{acin}}$ and $\mathrm{S}_{\text {cond }}$ were calculated after pooling all valid normalised slopes from the three MBW tests'; a typical example is shown in the online supplement. Additionally, LCI was computed as the number of lung turnovers when mean expired $\mathrm{N}_{2}$ concentration had reached 1/40th of the pretest alveolar $\mathrm{N}_{2}$ concentration; this was also done on the average of three $\mathrm{N}_{2}$ concentration washout curves (with each washout curve normalised to its pretest alveolar $\mathrm{N}_{2}$ concentration); the rationale and impact of using mean expired or end-tidal concentration for LCI computation is discussed elsewhere. ${ }^{27}$ From the SBW tests (pertaining to the core dataset), the phase III slope was determined over the entire expiration down to residual volume, and normalised by mean expired concentration. Depending on the SBW starting volume (FRC or RV), the normalised phase III slope is referred to as SnIII_FRC or SnIII_RV. For the SBW manuever starting from RV, the phase III slope is also reported as a non-normalised phase III slope (SIII_RV; in \%/litre) for ease of comparison with the literature. ${ }^{20} 23$

\section{Statistical analysis}

All statistical analyses were performed using MedCalc (V.10.4, Mariakerke, Belgium). Variables were tested for normality using the $\chi^{2}$ test. Multiple stepwise regressions were performed on $S_{\text {acin }}$, $\mathrm{S}_{\text {cond, }}$ LCI, SnIII FRC (log transformed), SnIII RV and SIII RV (log transformed), including gender, age, height and FRC as independent variables. A forward regression was used, setting the inclusion criterion for retention at $p<0.05$. When gender was retained as a significant factor, the multiple regression analysis was repeated for each gender. Plots of standardised residuals against standardised predicted values were visually inspected for the validity of linearity and homoscedacity. Analysis of covariance was used to test for differences in $\mathrm{S}_{\text {acin }}$, $\mathrm{S}_{\text {cond }}$ and LCI between the datasets from the two laboratories (factor: laboratory; covariate: age). Statistical significance was accepted at $p<0.05$. Bland Altman plots were used to examine agreement between manual $\mathrm{MBW}$ analysis by experts and semi-automated MBW analysis.

\section{RESULTS}

Summary data from the core and supplemental datasets are given in table 1; the table also includes SBW data from the core dataset. Figures $1-3$ show the $S_{\text {acin }}, S_{\text {cond }}$ and LCI increase as a function of age. In the multiple regression analyses on $S_{\text {acin }}, S_{\text {cond }}$ and LCI values of the core dataset, height or FRC did not reach statistical significance for inclusion in the regression model, while age was a significant contributor to all three $M B W$ indices $(p<0.001) ; S_{a c i n}$ was the only index showing a significant gender dependence $(p=0.002)$. Age-dependent regression equations corresponding to the core dataset can be found in table 2, with gender-specific equations only for $\mathrm{S}_{\mathrm{acin}}$. When dividing the regression slopes by the value obtained for a subject corresponding to the middle of the age range under study ( 45 years), these relative increases of $\mathrm{S}_{\mathrm{acin}}, \mathrm{S}_{\text {cond }}$ and LCI ranged $0.4-1.2 \%$ per year of increasing age. For comparison to SBW data in the literature, regression equations are also included for SBW-derived phase III slopes (table 3). In addition to age, height and FRC were independent predictors 
Table 1 Group data

\begin{tabular}{|c|c|c|c|c|c|c|c|c|}
\hline & \multicolumn{4}{|c|}{ Core dataset $(n=120)$} & \multicolumn{4}{|c|}{ Supplemental dataset $(n=60)$} \\
\hline & \multicolumn{2}{|c|}{ Women $(n=60)$} & \multicolumn{2}{|c|}{ Men $(n=60)$} & \multicolumn{2}{|c|}{ Women $(n=30)$} & \multicolumn{2}{|c|}{ Men $(n=30)$} \\
\hline & $\overline{\text { Avg }}$ & SD* & $\overline{\text { Avg }}$ & SD* & $\overline{\text { Avg }}$ & SD & $\overline{\text { Avg }}$ & SD \\
\hline Height (cm) & 166 & 5 & 179 & 7 & 162 & 7 & 172 & 18 \\
\hline Weight (kg) & 63 & 9 & 80 & 11 & 65 & 16 & 78 & 17 \\
\hline $\mathrm{FEV}_{1}$ (litres) & 2.9 & 0.4 & 4.1 & 0.8 & 2.7 & 0.6 & 3.8 & 0.6 \\
\hline \multicolumn{9}{|l|}{ MBW } \\
\hline $\mathrm{FRC}(\mathrm{ml})$ & 2839 & 491 & 3800 & 807 & 2673 & 585 & 3585 & 873 \\
\hline $\mathrm{LCl}$ & 6.26 & 0.44 & 6.28 & 0.39 & 5.77 & 0.50 & 5.65 & 0.49 \\
\hline $\mathrm{S}_{\text {cond }}\left(\right.$ litre $\left.^{-1}\right)$ & 0.035 & 0.014 & 0.034 & 0.010 & 0.036 & 0.018 & 0.036 & 0.015 \\
\hline $\mathrm{S}_{\text {acin }}\left(\right.$ litre $\left.^{-1}\right)$ & 0.083 & 0.030 & 0.099 & 0.032 & 0.086 & 0.037 & 0.091 & 0.041 \\
\hline \multicolumn{9}{|l|}{ SBW } \\
\hline
\end{tabular}

*When a variable was not normally distributed, median $(95 \% \mathrm{Cl})$ is shown instead.

Avg, average; FEV 1 , forced expiratory volume in one second; FRC, functional residual capacity; FVC, forced vital capacity; LCl, lung clearance index; MBW, multiple breath washout; RV, residual volume; SBW, single breath washout; $\mathrm{S}_{\text {cond }} \mathrm{S}_{\text {acin, }}$ multiple breath washout index of conductive and acinar ventilation heterogeneity; Snlll FRC, Snlll RV, normalised phase III slope of a single breath washout maneuver starting from functional residual capacity or residual volume; SIII RV, unnormalised phase III slope of a single breath washout maneuver starting from residual volume.

depending on the SBW maneuver and phase III slope normalisation. In fact, in the case of the vital capacity SBW, the phase III normalisation method determined whether the slope was different between both genders or not (SnIII_RV vs SIII_RV).

The panels $B$ of figures $1-3$ compare the core dataset to the supplemental dataset for $\mathrm{S}_{\text {acin }}, \mathrm{S}_{\text {cond }}$ and LCI. Analysis of covariance showed no difference between laboratories for $S_{\text {acin }}$

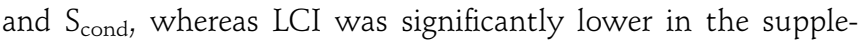
mentary versus the core data set (mean LCI difference -0.54; $p<0.0001)$. The prediction of why such a difference should be more pronounced for LCI than for $\mathrm{S}_{\text {acin }}$ or $\mathrm{S}_{\text {cond, }}{ }^{30}$ and some additional experiments to verify this, can be found in the online supplement. Also included in an online supplement are the specifications of an automated $\mathrm{MBW}$ analysis, applying a recently proposed break point algorithm. ${ }^{29}$ Using this tech- nique, we re-analysed half the core dataset (in order of subject entry) and the resulting Bland-Altman plots in figure 4 show that, for the most difficult parameters to obtain automatically $\left(\mathrm{S}_{\text {acin }}\right.$ and $\left.\mathrm{S}_{\text {cond }}\right)$, a good agreement between automated and manual analysis was obtained.

\section{DISCUSSION}

While normal ageing has been shown to be associated with decreased lung compliance and decline in airway diameter, ${ }^{31}$ little is known about intrapulmonary heterogeneity of these changes with age. Since ventilation heterogeneity involves dynamic processes, and cannot be reduced to static morphometric properties such as airway wall thickness, physiological tests of ventilation heterogeneity are the only way to investigate this. In the present study, we have quantified the age-dependent
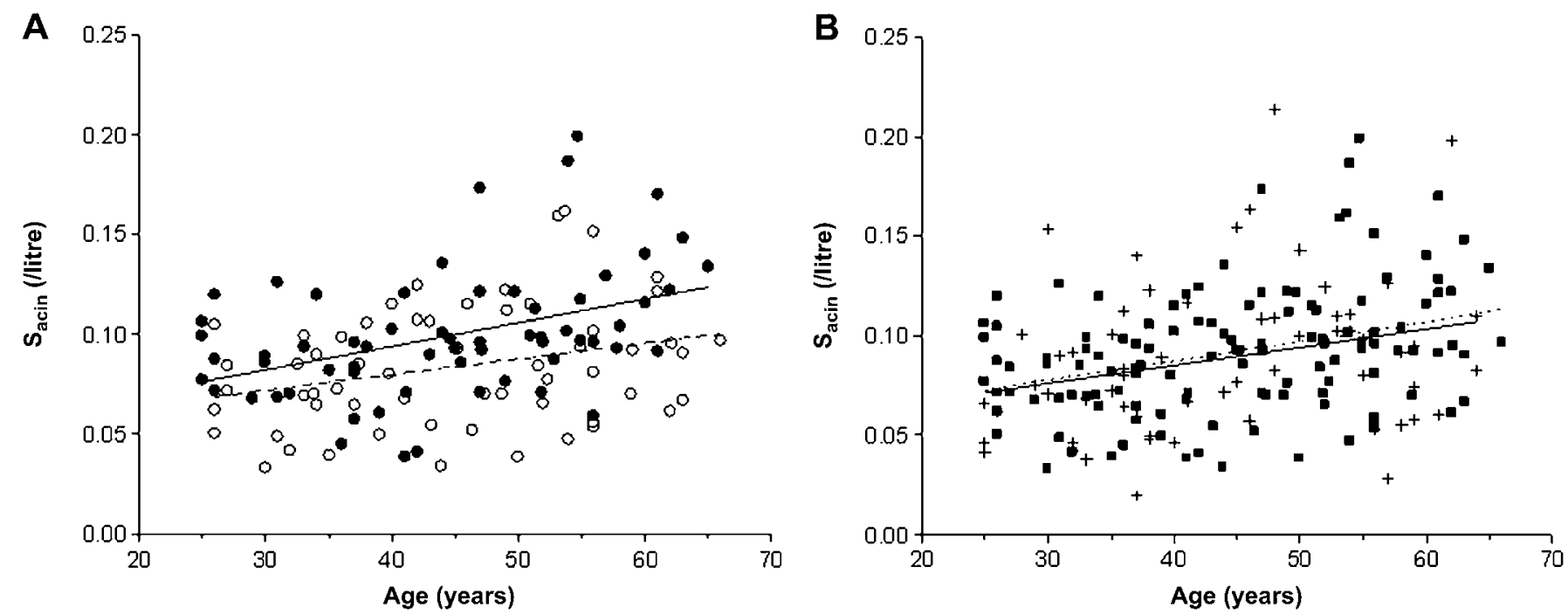

Figure 1 Scatterplots of $S_{\text {acin }}$ versus age. (A) Core datasets with corresponding regression lines for women (open symbols; dashed line) and men (closed symbols; solid line). (B) Core dataset pooling women and men (closed squares; dotted line) and supplementary dataset (crosses; solid line) with corresponding regression lines. $S_{\text {acin, }}$ ventilation heterogeneity generated peripheral to the acinar entrance. 

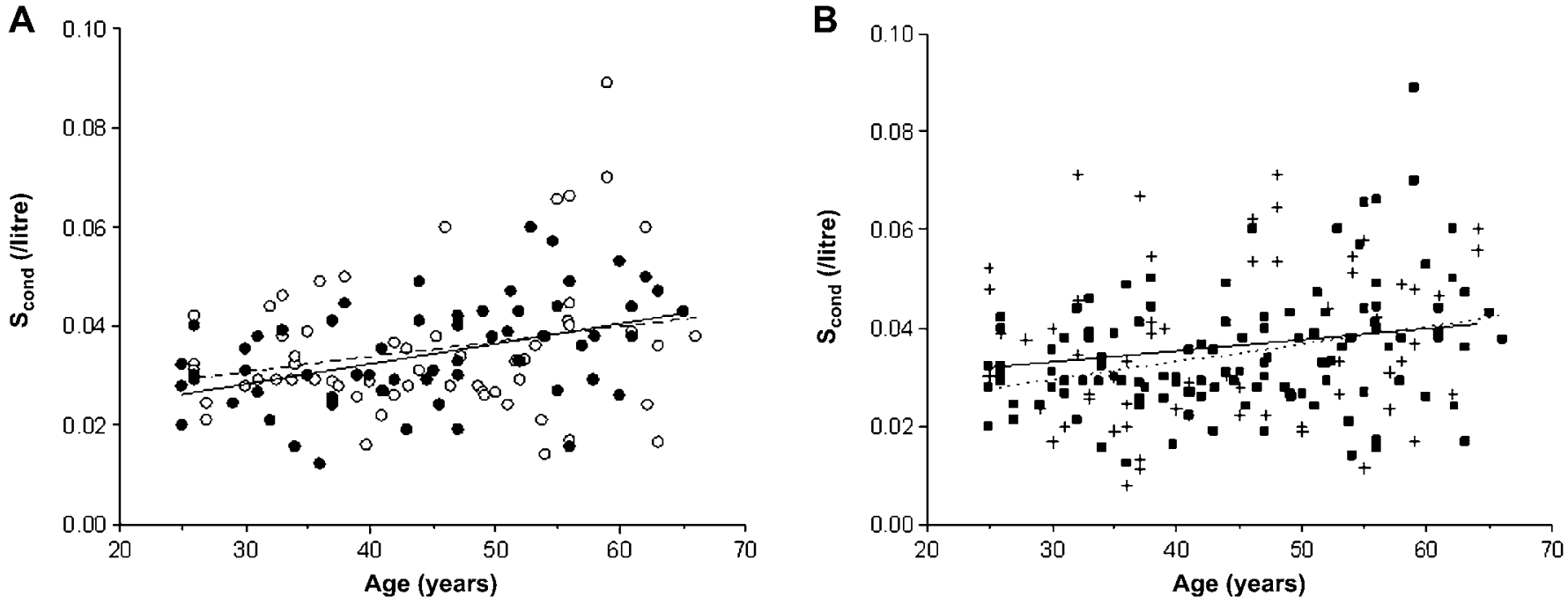

Figure 2 Scatterplots of $S_{\text {cond }}$ versus age. (A) Core datasets with corresponding regression lines for women (open symbols; dashed line) and men (closed symbols; solid line). (B) Core dataset pooling women and men (closed squares; dotted line) and supplementary dataset (crosses; solid line) with corresponding regression lines. $S_{\text {cond, }}$ ventilation heterogeneity generated in the conductive lung zone.

change of ventilation heterogeneity in different lung zones via the MBW test, demonstrating a significant age dependence on $\mathrm{S}_{\text {acin }}, \mathrm{S}_{\text {cond }}$ and LCI in healthy never-smoker subjects. Height was shown not to have a significant impact on any of the three $\mathrm{MBW}$ indices under study, and gender affected only $\mathrm{S}_{\text {acin. }}$. The age dependence of $S_{\text {acin }}$ was very similar across both gender subgroups (figure 1A). The largest absolute $S_{\text {acin }}$ difference between men and women (estimated at 65 years (table 2): $0.025 /$ litre) was small with respect to values encountered in disease when $S_{\text {acin }}$ typically amounts to 0.2 litre $^{-1}$ in moderate asthma $^{13}$ and rises to $0.3-0.4$ litre $^{-1}$ in patients with chronic obstructive pulmonary disease depending on the presence of emphysema. ${ }^{10}$ Nevertheless, when setting up clinical studies for early detection purposes, the gender dependence of $\mathrm{S}_{\text {acin }}$ may need to be taken into account.

The slightly greater $S_{\text {acin }}$ in men could have suggested that the intra-acinar bifurcation pattern that is a major determinant of acinar ventilation heterogeneity is more asymmetric in men.
However, we contend that the observed gender difference in $\mathrm{S}_{\mathrm{acin}}$ is more likely due to the fact that inherent to $\mathrm{MBW}, \mathrm{S}_{\mathrm{acin}}$ is based on a normalised phase III slope from an exhalation that has been truncated at 1 litre instead of exhalation to residual volume. This can be inferred from comparison of $\mathrm{S}_{\text {acin }}$ with the SBW-derived SnIII_FRC, which is computed from an exhalation that continues to residual volume, such that all acinar ventilation heterogeneities can fully contribute to the phase III, that is, to its slope and to the mean expired concentration (by which the phase III slope is to be normalised). When dividing the maximum $S_{\text {acin }}$ difference between men and women (occurring at 65 years: $0.025 /$ litre) by its average $S_{\text {acin }}$ value $\left(0.111\right.$ litre $\left.{ }^{-1}\right)$ predicted from the equations in table 2 , we obtain a relative difference between men and women of $22 \%$. The corresponding number based on the prediction equations in table 3 for SnIII_FRC amounts to only $3 \%$ (in this case, average heights and weights from table 1 are used to compute the predicted values for men and women of SnIII_FRC). At lower ages the
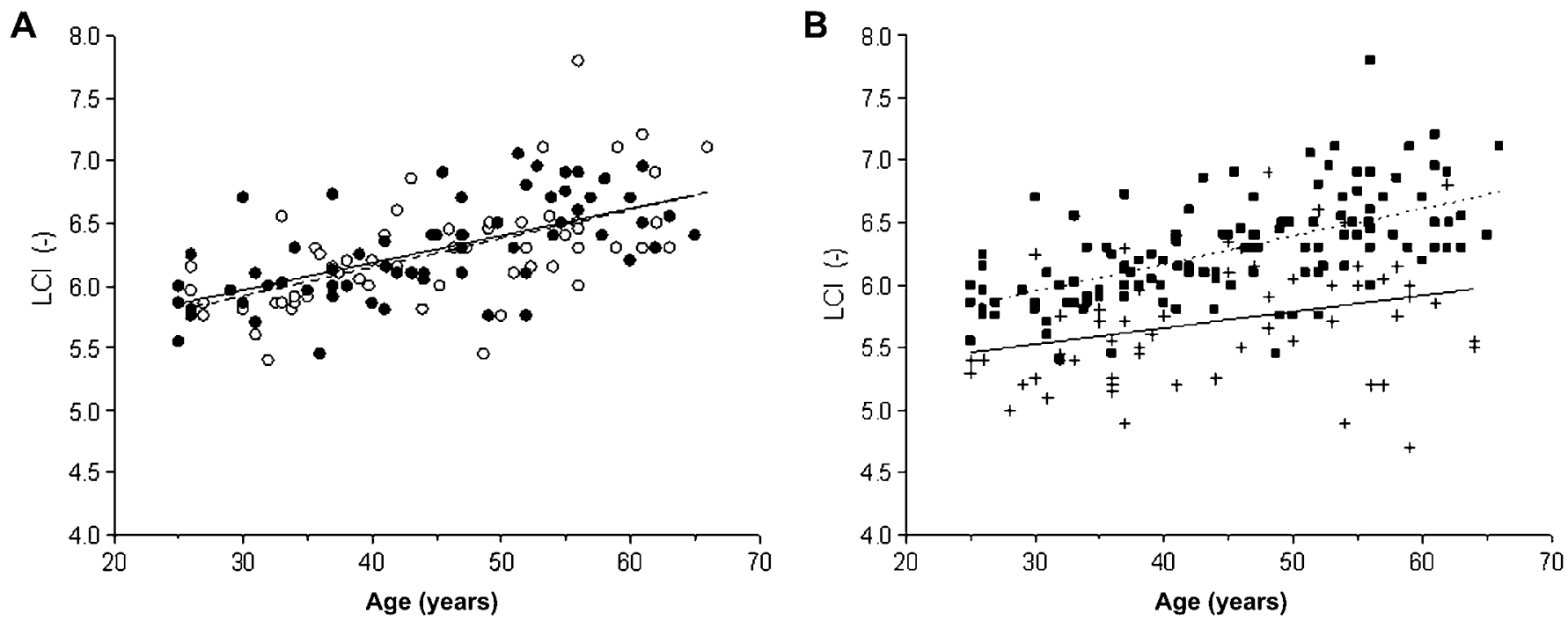

Figure 3 Scatterplots of $\mathrm{LCl}$ versus age. (A) Core datasets with corresponding regression lines for women (open symbols; dashed line) and men (closed symbols; solid line). (B) Core dataset pooling women and men (closed squares; dotted line) and supplementary dataset (crosses; solid line) with corresponding regression lines. $\mathrm{LCl}$, lung clearance index. 
Table 2 Regression equations for multiple breath washout indices from the core dataset $(n=120)$

\begin{tabular}{llll}
\hline & & Adjusted $\mathbf{R}^{2}$ & Residual, standard, deviation \\
\hline $\begin{array}{l}\text { LCI } \\
\quad \text { Men/women pooled }\end{array}$ & $0.0223^{*}$ age +5.275 & 0.36 & 0.330 \\
$\begin{array}{l}\mathrm{S}_{\text {cond }} \text { (/litre) } \\
\text { Men/women pooled }\end{array}$ & $0.000358^{*}$ age +0.0187 & 0.10 & 0.0116 \\
$\mathrm{~S}_{\text {acin }}$ (/litre) & & \\
$\quad$ Women & $0.00078^{*}$ age +0.0482 & 0.07 & 0.0291 \\
$\quad$ Men & $0.00118^{*}$ age +0.0472 & 0.16 & 0.0294 \\
\hline LCl, lung clearance index; $\mathrm{S}_{\text {cond }} \mathrm{S}_{\text {acin }}$ multiple breath washout index of conductive and acinar ventilation heterogeneity.
\end{tabular}

dependence of $S_{\text {acin }}$ and SnIII_FRC on gender is even reversed, depending also on the choice of FRC and height in the case of SnIII_FRC. Hence, we conclude that the gender dependence of $\mathrm{S}_{\text {acin }}$, which is not negligible with respect to the low $S_{\text {acin }}$ values in normal subjects, is an intrinsic feature of $\mathrm{MBW}$ normalised phase III slope analysis and a tradeoff to enable the distinction between acinar and conductive ventilation heterogeneities in lung disease.

Distinct gender differences were observed in the very first physiological investigations of the age dependence of ventilation distribution, ${ }^{17}{ }^{18}$ using the phase III slope derived from the SBW maneuver starting from FRC. While this was in large part due to absence of phase III slope normalisation, later studies using the vital capacity SBW maneuver also showed a gender difference in phase III slope. ${ }^{20} 23$ For this SBW maneuver, the SIII_RV difference is opposite to that for $S_{\text {acin }}$, essentially due to a slightly greater RV/TLC in women versus men. ${ }^{20} 23$ For a 45-year-old woman versus a 45 -year-old man, predicted SIII_RV is 1.21 vs $0.96 \% /$ litre in the present study, 1.40 vs $1.04 \% /$ litre in the Portland cohort in Buist et $a l^{20}$ and $1.11 \mathrm{vs}$ $0.88 \% /$ litre in a London cohort in Roberts et al. ${ }^{23}$ When normalising the vital capacity SBW phase III slope by mean expired concentration in the present study, the gender gap disappears altogether (SnIII_RV in table 3).

The LCI dependence on age was consistent, despite an absolute LCI difference between both participating laboratories associated with an equipment dead space (ie, re-inspired dead space) difference. Since the value of this particular dead space essentially depends on the valve system, this cannot be realistically imposed on all laboratories wanting to incorporate MBW tests in their lung function equipment. Despite the many potential equipment and methodological differences between our study and that by Bouhuys in $1963,{ }^{32}$ the LCI they measured (in men 24-65 years) showed an increase between the average value reported for the lowest and highest decade (9.1 vs
10.0). The increase in LCI with age found in this study in adults is in contrast to what was previously reported in children and adults. ${ }^{726}$ The observed 0.22 unit LCI change per decade found in this study is also not negligible with respect to what is thought to be a clinically relevant LCI difference of typically 0.45 between a healthy control group and an asthma group. ${ }^{4}$ Clearly, when studying ventilation heterogeneity in terms of LCI in adults, age is a small but consistent factor that needs to be acknowledged.

The relative increases in the three $\mathrm{MBW}$ indices with age are small, ranging from $0.4 \%$ (for $\mathrm{LCI}$ ) to $1.2 \%$ (for $\mathrm{S}_{\text {acin }}$ ), yet, the actual impact of age on LCI or on $S_{\text {acin }}$ can also be illustrated as follows. For a 25-year-old subject, the LCI upper limit of normal (computed as the predicted value $+1.645 *$ residual standard deviation) would be 6.39 , which corresponds to the predicted value of a normal 50 year old. With a similar reasoning, the $S_{\text {acin }}$ and $S_{\text {cond }}$ upper limit of normal for a 25 -year-old subject would correspond to the respective predicted values for subjects older than 65 years. Together with the greater $\mathrm{R}^{2}$ value for LCI, this example illustrates that it is even more important for LCI than for $\mathrm{S}_{\text {acin }}$ or $\mathrm{S}_{\text {cond }}$ to factor in age when using these MBW indices as diagnostic tools. Absolute values for the upper limits of normal for LCI, $\mathrm{S}_{\text {acin }}$ or $\mathrm{S}_{\text {cond }}$ may differ between laboratories, depending on instrumental dead space (expected to affect primarily LCI) but also the test gas used (expected to affect primarily LCI and $S_{\text {acin }}$ ). Given the slow and linear increase in all three MBW indices in this age range, any local set of reference values can be obtained by performing a reasonable number of MBW tests in normal subjects at either end of the 25-65-year age range, followed by linear interpolation.

All things considered, the variability explained by age was low (table 2 ), ranging only from $7 \%$ to $16 \%$ for $S_{\text {acin }}$ and $S_{\text {cond }}$. Despite such weak age relationships, we did observe virtually the same age dependence of $S_{\text {acin }}$ and $S_{\text {cond }}$ on a totally different set of 60 normal subjects collected in a different laboratory.

Table 3 Regression equations for single breath washout indices from the core dataset $(n=120)$

\begin{tabular}{llll}
\hline & & Adjusted $\mathbf{R}^{2}$ & Residual, standard, deviation \\
\hline SnIII_FRC (/litre) & $\mathrm{e}^{(0.0227 * \text { age }-0.583 * \mathrm{FRC}+2.08 * \text { height }-5.955)}$ & 0.60 & 0.297 \\
$\quad$ Women & $\mathrm{e}^{(0.0363 * \text { age }-0.537 * \mathrm{FRC}-2.644)}$ & 0.72 & 0.357 \\
$\quad$ Men & & \\
SnIII_RV (/litre) & & 0.18 & 0.016 \\
$\quad$ Men/women & $0.000646 *$ age $+0.00534 *$ FRC +0.0372 & & \\
SIII_RV (\%/litre) & $\mathrm{e}^{(0.0204 * \text { age }-0.726)}$ & 0.29 & 0.342 \\
Women & $\mathrm{e}^{(0.0285 * \text { age }-1.325)}$ & 0.48 & 0.307 \\
Men &
\end{tabular}

Age in years, height in metres, and FRC in litres.

FRC, functional residual capacity; SnllI FRC, Snlll RV, normalised phase III slope of a single breath washout maneuver starting from functional residual capacity or residual volume; SIII_RV, unnormalised phase III slope of a single breath washout maneuver starting from residual volume. 
Figure 4 Bland-Altman plots comparing (A) $\mathrm{S}_{\text {acin, }}$ (B) $\mathrm{S}_{\text {cond }}$ (C) LCl and (D) FRC values computed either manually or with an automated procedure. FRC, functional residual capacity; LCl, lung clearance index; $S_{\text {acin, }}$ ventilation heterogeneity generated peripheral to the acinar entrance; $\mathrm{S}_{\text {cond, }}$ ventilation heterogeneity generated in the conductive lung zone.

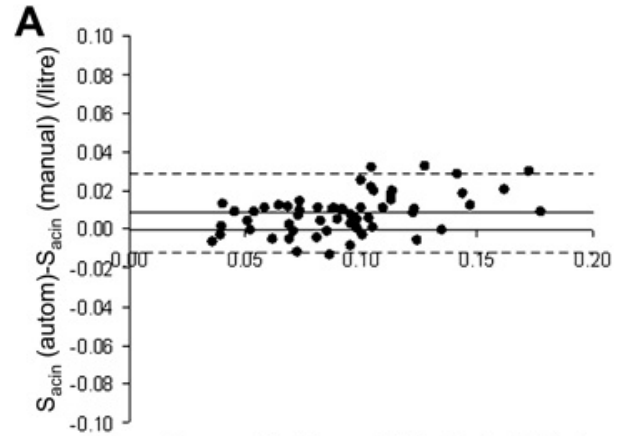

Average $\mathrm{S}_{\text {acin }}$ (manual), $\mathrm{S}_{\text {acin }}$ (autom) (/litre)

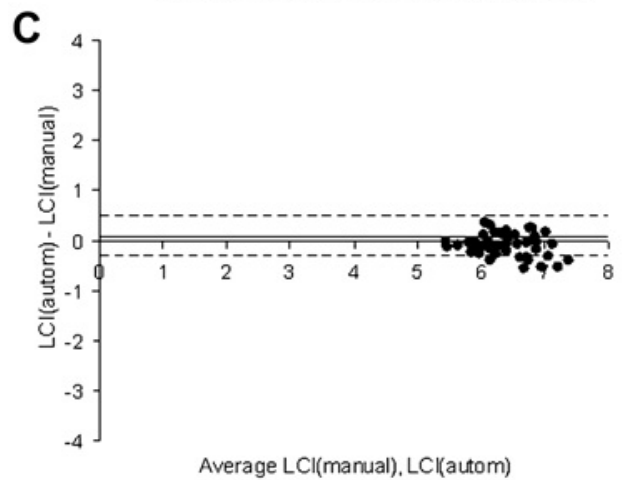

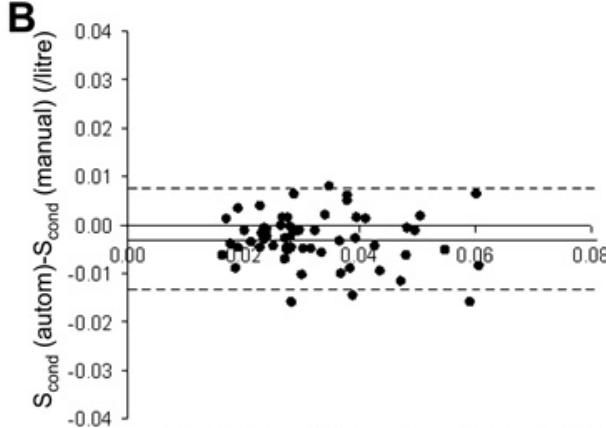

Average $\mathrm{S}_{\text {cond }}$ (manual), $\mathrm{S}_{\text {cond }}$ (autom) (/litre)

D

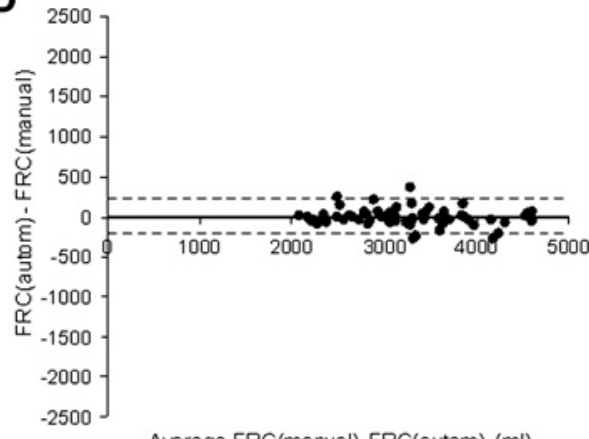

Previous studies have shown $\mathrm{S}_{\text {acin }}$ and $\mathrm{S}_{\text {cond }}$ to be reproducible (eg, Downie et $a l^{15}$ ), and the inter-subject differences in $S_{\text {acin }}$ and $\mathrm{S}_{\text {cond }}$ that are not related to age should be interpreted in terms of inter-subject differences in lung structure. Based on the fundamental principles laid out in the online supplement, it is reasonable to assume that $S_{\text {acin }}$ and $S_{\text {cond }}$ are particularly associated with subject-specific heterogeneity of lung structures in a way that is very different from spirometric volumes. For instance, $S_{\text {acin }}$ is critically dependent on average acinar branching asymmetry as well as on parallel variability in branching asymmetry, ${ }^{33}$ which is likely to be different between subjects despite similar overall lung architecture. The same is probably

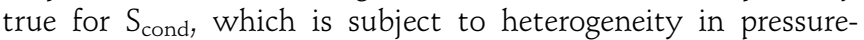
volume characteristics of lung units larger than acini and heterogeneity in bronchomotor tone of conductive airways subtending these. ${ }^{9}$

Two computational sources of variability of phase III slope analysis, particularly in normal subjects, are relatively flat phase III slopes, and perturbations from cardiogenic oscillations. These phase III features are particularly challenging when trying to automate computation, but we show here that this is certainly feasible (figure 4). The fact that in lung disease phase III slopes are greater and cardiogenic oscillations are mostly absent makes automated slope computation a realistic option with a perspective of practical clinical applicability. In the early days of computing power, automation of SBW phase III slope calculation was pursued with the perspective of using it as an epidemiological tool. ${ }^{28}$ In the SBW, automation was aimed at determining the break point between phase III and phase IV, ${ }^{28}$ while for the MBW the issue is finding the break point between phase II and phase III. ${ }^{29}$

In summary, it has long been known that non-invasive measurement of gas concentrations at the mouth of a patient can provide important information about ventilation heterogeneity, and be a marker of structural abnormality in the small airways. A consistent finding in the present MBW study is that ventilation becomes gradually more heterogeneous as adults grow older between the age of 25 and 65 years, both in conductive and acinar lung zones. The extent of age dependence with respect to intrinsic variability of the MBW indices clearly shows that age is a crucial parameter to be factored in when using these MBW indices as diagnostic tools. Finally, from the methodological issues covered in the online supplement we can summarise that the re-inspired instrumental dead space volume plays a predictable role, with the most marked effect on LCI, and that the $\mathrm{MBW}$ analysis in terms of $S_{\text {acin }}$ and $S_{\text {cond }}$-requiring phase III slope determination-can be automated.

Contributors Study design, data acquisition, analysis, and writing up results: all authors. Interpretation and supervision of final draft: SV, BRT, OSU.

Funding This study was funded by the Fund for Scientific Research-Flanders and supported by the National Institute of Health Research (NIHR) Respiratory Disease Biomedical Research Unit at the Royal Brompton and Harefield NHS Foundation Trust and Imperial College London. Dr O S Usmani is a recipient of an NIHR Career Development Fellowship. B R Thompson also received financial support through the National Health and Medical Research Council of Australia (grants 486101 and 491103).

Competing interests None.

Ethics approval Research ethics committees of UZ Brussel (B14320097554) and Brompton Hospital (08/H0709/2).

Provenance and peer review Not commissioned; externally peer reviewed.

\section{REFERENCES}

1. Burgel PR. The role of small airways in obstructive airway diseases. Eur Respir Rev 2011:20:23-33.

2. Usmani OS, Barnes PJ. Assessing and treating small airways disease in asthma and chronic obstructive pulmonary disease. Ann Med 2012:44:146-56.

3. Aurora P. Multiple-breath inert gas washout test and early cystic fibrosis lung disease. Thorax 2010;65:373-4.

4. Macleod KA, Horsley AR, Bell NJ, et al. Ventilation heterogeneity in children with well controlled asthma with normal spirometry indicates residual airways disease. Thorax 2009;64:33-7.

5. Horsley AR, Gustafsson PM, Macleod KA, et al. Lung clearance index is a sensitive repeatable and practical measure of airways disease in adults with cystic fibrosis. Thorax 2008:63:135-40.

6. Becklake MR. A new index of the intrapulmonary mixture of inspired air. Thorax 1952; 7:111-16. 
7. Aurora P, Kozlowska W, Stocks J. Gas mixing efficiency from birth to adulthood measured by multiple-breath washout. Respir Physiol Neurobiol 2005;148:125-39

8. Crawford AB, Makowska M, Paiva M, et al. Convection- and diffusion-dependent ventilation maldistribution in normal subjects. J Appl Physiol 1985;59:838-46.

9. Verbanck S, Paiva M. Gas mixing in the airways and air spaces. Compr Physiol 2011:1:809-34

10. Verbanck S, Schuermans D, Meysman M, et al. Noninvasive assessment of airway alterations in smokers: the small airways revisited. Am J Respir Crit Care Med 2004;170:414-19.

11. Verbanck S, Schuermans D, Van Muylem A, et al. Conductive and acinar lung-zone contributions to ventilation inhomogeneity in COPD. Am J Respir Crit Care Med 1998:157:1573-7.

12. Timmins S, King GG, Schoeffel R, et al. The relationship between emphysema extent and ventilation heterogeneity. Am J Respir Crit Care Med 2011;183:A5786.

13. Verbanck S, Schuermans D, Paiva M, et al. The functional benefit of antiinflammatory aerosols in the lung periphery. J Allergy Clin Immunol 2006:118:340-6.

14. Verbanck S, Schuermans D, Vincken W. Inflammation and airway function in the lung periphery of patients with stable asthma. J Allergy Clin Immunol 2010;125:611-16.

15. Downie SR, Salome CM, Verbanck $S$, et al. Ventilation heterogeneity is a major determinant of airway hyperresponsiveness in asthma, independent of airway inflammation. Thorax 2007;62:684-9.

16. Sonnappa S, Bastardo CM, Wade A, et al. Symptom-pattern phenotype and pulmonary function in preschool wheezers. J Allergy Clin Immunol 2010;126:519-26

17. Sandqvist L, Kjellmer I. Normal values for the single breath nitrogen elimination test in different age groups. Scand J Clin Lab Invest 1960:12:131-5.

18. Stănescu D, Teculescu D, Păcuraru R. Reproducibility and normal values of the single breath nitrogen test. Scand J Respir Dis 1968;49:322-30.

19. Guy HJ, Prisk GK, Elliott AR, et al. Inhomogeneity of pulmonary ventilation during sustained microgravity as determined by single-breath washouts. J Appl Physiol 1994:76:1719-29
20. Buist AS, Ghezzo $\mathrm{H}$, Anthonisen NR, et al. Relationship between the single-breath $\mathrm{N}$ test and age, sex, and smoking habit in three North American cities. Am Rev Respir Dis 1979;120:305-18

21. Knudson RJ, Lebowitz MD, Burton AP, et al. The closing volume test: evaluation of nitrogen and bolus methods in a random population. Am Rev Respir Dis 1977:115:423-34.

22. Sixt R, Bake B, Oxhöj $\mathrm{H}$. The single-breath $\mathrm{N}_{2}$-test and spirometry in healthy non-smoking males. Eur J Respir Dis 1984;65:296-304.

23. Roberts CM, MacRae KD, Winning AJ, et al. Reference values and prediction equations for normal lung function in a non-smoking white urban population. Thorax 1991:46:643-50.

24. Gillooly M, Lamb D. Airspace size in lungs of lifelong non-smokers: effect of age and sex. Thorax 1993:48:39-43

25. Waters B, Owers-Bradley J, Silverman M. Acinar structure in symptom-free adults by helium-3 magnetic resonance. Am J Respir Crit Care Med 2006;173:847-51.

26. Horsley AR, Macleod KA, Robson AG, et al. Effects of cystic fibrosis lung disease on gas mixing indices derived from alveolar slope analysis. Respir Physiol Neurobiol 2008;162:197-203

27. Verbanck S, Paiva M, Schuermans D, et al. Relationships between the lung clearance index and conductive and acinar ventilation heterogeneity. J Appl Physiol 2012;112:782-90.

28. Craven N, Sidwall G, West $P$, et al. Computer analysis of the single-breath nitrogen washout curve. Am Rev Respir Dis 1976:113:445-9.

29. Stuart-Andrews C, Kelly C, Sands S, et al. Automated detection of the phase III slope during inert gas washout testing. J Appl Physiol 2012;112:1073-81.

30. Emery MJ, Hildebrandt J, Hlastala MP. Ventilation heterogeneity in excised lobes: effect of tidal volume. J Appl Physiol 2000;88:1659-71.

31. Janssens JP, Pache JC, Nicod LP. Physiological changes in respiratory function associated with ageing. Eur Respir J 1999;13:197-205.

32. Bouhuys A. Pulmonary nitrogen clearance in relation to age in healthy males. J App/ Physiol 1963:18:297-300.

33. Dutrieue B, Vanholsbeeck F, Verbanck S, et al. A human acinar structure for a realistic simulations of the alveolar slope. J Appl Physiol 2000:89:1859-67.

Thorax online

Visit Thorax online and listen to the latest podcast, post comments and download any you might have missed. Keep informed and up to date by visiting thorax.bmj.com. 